\title{
INVESTIGATION ON ANXIETY AND COPING STYLE OF COLLEGE STUDENTS DURING COVID-19 EPIDEMIC
}

\author{
Yinghua Zhao \\ Yancheng Institute of Technology, Yancheng, Jiangsu, China
}

received: 2.7.2021;

revised: 5.10.2021;

accepted: 18.10 .2021

\begin{abstract}
SUMMARY
Background: To investigate the current situation of anxiety and coping style of college students during COVID-19 epidemic.

Subjects and methods: In February, 2021, 620 college students studying at home were investigated by online questionnaire, and the data were collected by self-rating anxiety scale and simple coping style questionnaire.

Results: Some students had behavioral reactions and somatization symptoms such as panic, anxiety, depression, boredom and depression. There are differences in coping styles among college students of different genders and grades, and some coping styles are related to anxiety. The better the knowledge of epidemic prevention or the more active the coping style, the lower the anxiety level. The more negative the coping style, the higher the anxiety.

Conclusions: During COVID-19 epidemic, there are differences in coping styles among college students of different genders and grades, and some coping styles are related to anxiety. Schools and society should pay attention to the coping style and mental health counseling of candidates while preventing and controlling the epidemic.
\end{abstract}

Key words: COVID-19 - college students - anxiety - coping style

$* * * * *$

\section{INTRODUCTION}

As we all know, college students are in a special period of physical and mental development, and at a critical stage of the formation of outlook on life, values and world outlook. Social life stress events, such as the outbreak of major epidemics, often have complex and profound multiple impacts on their body and mind. Relevant research at home and abroad has shown that social life stress events, major setbacks and ineffective coping are often the main reasons for college students' psychological problems (Zhu et al. 2020). The appearance of COVID-19 not only harms people's health, but also makes people have some psychological problems of anxiety and panic, which is no exception among college students (Abuhmain \& Al-Majali 2020, Karasar \& Canli 2020).

At present, the research on individual mental health and coping style during COVID-19 epidemic mainly focuses on medical staff, general population and COVID-19 patients ( $\mathrm{Li}$ et al. 2019, Son et al. 2020), while the research on coping style of college students and its relationship with anxiety is rare. The purpose of this study is to explore the characteristics of college students' coping style during COVID-19 epidemic and its relationship with anxiety, so as to provide reference for improving college students' mental health after the epidemic.

There are several factors in anxiety. The first factor is helplessness and insecurity. When faced with danger, people may become active and courageous, but they are in a state of anxiety. Another factor of anxiety is irrationality. Because of this irrational factor of anxiety, anxiety shows a hidden warning, that is, something inside us will get out of control, so it needs to control some- thing inside us. Not only do we consciously regard it as a challenge, but we also secretly think that we are challenging, whether we choose to admit this attitude or not.

Anxiety, as an emotional and psychological problem, has certain manifestations in daily life. Often manifested as shallow and fast breathing, sweating skin, difficulty in falling asleep, poor sleep, blocked thinking, inflexible behavior, slow movement, narrow attention, nervousness, uneasiness, worry, worry, fear, expectation, irritability, easy to get angry and so on (Zhang et al. 2019). There is a certain relationship between anxiety and expectation. Generally, the higher the expectation is, the more anxiety is. For example, the anxiety is higher before the stage speech or performance, before the exam, on the eve of major events or turning points in life (Mubeen et al. 2019).

Anxiety, as a negative emotion, not only brings positive influence to people, but also brings negative side to people. It often puts individuals in a state of fear, uneasiness and anxiety, thus causing problems such as tension, uneasiness, annoyance, irritability, fatigue and sleep disorder. It is often accompanied by some autonomic nervous uneasiness, which has a certain degree of influence on the individual's psychology and physiology. If the individual is troubled by anxiety for a long time, it will also lead to depression and even suicide in severe cases (Fu et al. 2020).

\section{SUBJECTS AND METHODS}

In February, 2021, college students were selected by convenient sampling method, and based on the principle of voluntary participation, the online questionnaire "Evaluation and Investigation of Children and Adolescents' 
Psychological Status under Epidemic Situation" was filled out. Inclusion criteria: college students aged 1318; Voluntary participation. Exclusion criteria: students taking off semester. A total of 620 questionnaires were collected, of which 620 were valid, and the recovery rate of valid questionnaires was $100 \%$. This investigation and study has been approved by the relevant Council members.

Self-rating anxiety scale, which was developed by w.k. Zung in 1971. This scale contains 20 items reflecting subjective feelings of anxiety, including 15 positive scores and 5 negative scores. Each item is scored according to the frequency of symptoms, and the scores of all items are accumulated. The higher the total score, the higher the degree of anxiety (Huang et al. 2019). In this study, the Cronbach $\alpha$ coefficient of the scale is 0.836 , and the structural validity is good.

Coping Style Scale. A total of 30 questions in the College Students Coping Style Scale are assigned 0 5 points according to the frequency of the adopted methods, which are used to evaluate six different coping styles of college students, such as problem solving, rescue, retreat, venting, fantasy and patience. The Cronbacha $\alpha$ coefficient of the scale is 0.77 .

\section{Statistical Analysis}

The results of the questionnaire were imported into SPSS 22.0 software. Qualitative data were described by frequency and percentage, while quantitative data were described by $(\overline{\mathrm{x}} \pm \mathrm{s})$. Univariate analysis of variance, $\mathrm{T}$ test of two independent samples and Pearson correlation analysis were carried out. The level $p<0.05$ is statistically significant.

\section{RESULTS}

\section{Current situation and coping style of college students' anxiety}

It was found that the college students in the period of coping with the epidemic at home showed emotional problems in different degrees, such as panic, anxiety, depression, anxiety and so on. Among them, most students expressed boredom and depression (see Figure 1).

In addition, $13.1 \%$ of the students indicated that they suffered from insomnia, fidgeting, suppressing yelling and making trouble without reason. In addition, $44.48 \%$ students' families showed the above emotional state, $13.53 \%$ students' families showed the above behavioral reaction, and $4.52 \%$ students indicated that they were easily influenced by their families. When stress events such as major social epidemic or personal setback occur, it is normal for individuals to have bad emotions. We should guide students to calmly analyze the specific reasons and find effective adjustment methods on the premise of accepting and recognizing bad emotions.

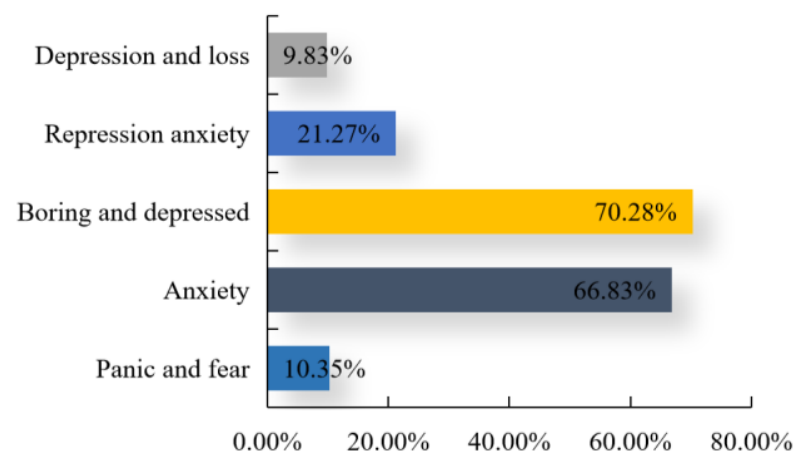

Figure 1. Emotional status of college students during epidemic prevention and control at home

As far as college students are concerned, the most important thing is to arrange their home life and study scientifically and reasonably. However, in the investigation, we found that some students' life content was monotonous and they relied too much on the Internet (see Figure 2).

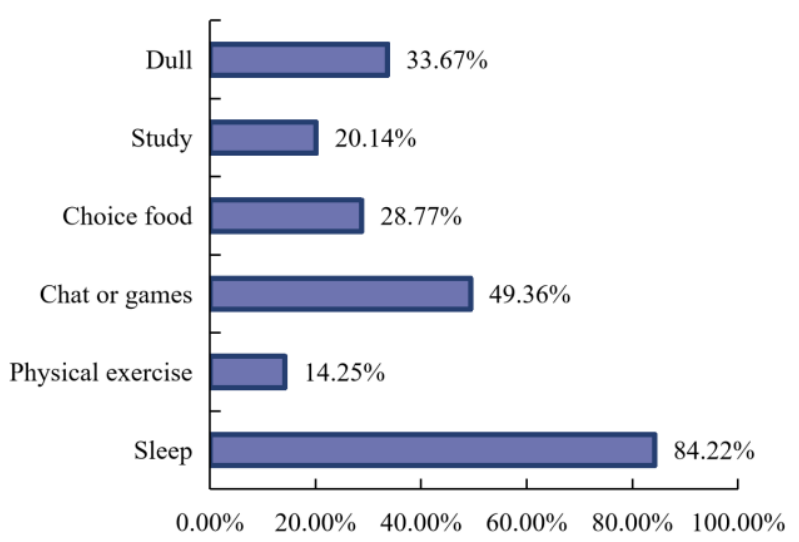

Figure 2. What college students do during home control

Table 1. Comparison of coping style scale scores of college students of different genders and grades

\begin{tabular}{lcccc}
\hline Group & Keep patience & Escape & Vent one's emotions & Fantasy/denial \\
\hline Gender & & & & \\
Schoolboy $\quad(\mathrm{n}=339)$ & $9.21 \pm 2.33$ & $7.38 \pm 2.17$ & $7.83 \pm 2.89$ & $9.33 \pm 3.47$ \\
Girl student $\quad(\mathrm{n}=281)$ & $9.36 \pm 2.08$ & $7.44 \pm 2.48$ & $8.37 \pm 2.88$ & $9.51 \pm 3.56$ \\
Grade & & & & \\
Freshman & $9.01 \pm 2.37$ & $7.29 \pm 2.43$ & $7.96 \pm 2.83$ & $9.24 \pm 3.49$ \\
Junior & $9.68 \pm 2.66$ & $7.86 \pm 2.77$ & $8.41 \pm 2.42$ & $9.78 \pm 3.54$ \\
t & -0.76 & -0.43 & -2.15 & -1.16 \\
P & 0.44 & 0.68 & 0.01 & 0.22 \\
\hline
\end{tabular}


Table 2. Comparison of various factors of coping style among those with or without test anxiety

\begin{tabular}{lcccc}
\hline Coping style & Have test anxiety & No test anxiety & $\mathrm{t}$ & $\mathrm{P}$ \\
\hline Solve problems & $23.58 \pm 5.22$ & $27.81 \pm 6.18$ & 4.01 & 0.00 \\
Seek help & $18.71 \pm 4.31$ & $21.39 \pm 5.66$ & 2.36 & 0.01 \\
Withdraw and avoid & $15.24 \pm 3.62$ & $3.38 \pm 3.16$ & 1.28 & 0.06 \\
Unleash & $10.28 \pm 2.29$ & $10.96 \pm 3.22$ & -1.08 & 0.05 \\
Illusion & $8.96 \pm 2.33$ & $7.71 \pm 2.91$ & -1.41 & 0.12 \\
Keep patience & $10.16 \pm 2.01$ & $9.88 \pm 2.41$ & -0.17 & 0.86 \\
\hline
\end{tabular}

Table 3. Stepwise regression analysis of epidemic prevention achievements and coping styles on anxiety

\begin{tabular}{|c|c|c|c|c|c|c|}
\hline $\begin{array}{l}\text { Dependent } \\
\text { variable }\end{array}$ & Predictor variable & $\begin{array}{l}\text { Partial regression } \\
\text { coefficient }\end{array}$ & $\begin{array}{c}\text { Standard regression } \\
\text { coefficient }\end{array}$ & $\mathrm{t}$ & $\mathrm{R}^{2}$ & $\mathrm{~F}$ \\
\hline \multirow{3}{*}{$\begin{array}{l}\text { Anxiety } \\
\text { state }\end{array}$} & Epidemic prevention knowledge & -0.041 & -0.087 & -3.286 & & \\
\hline & Actively respond & -6.257 & -0.516 & -19.249 & 0.227 & 160.17 \\
\hline & Negative coping & 4.338 & 0.221 & 11.873 & & \\
\hline
\end{tabular}

\section{Comparison of coping style scale scores of college students of different genders and grades}

The vent emotion dimension score of coping style scale for girls was higher than that of boys, and the difference was statistically significant $(\mathrm{P}<0.01)$. The scores of problem-solving dimensions of freshmen were lower than those of juniors, while the scores of patience, escape, venting emotions and fantasy/denial were higher than those of juniors, with statistical significance $(\mathrm{P}<0.05$ or 0.01$)$. See table 1 .

\section{Comparison of college students' coping styles}

By analyzing the factors of coping style of students with or without test anxiety, Table 2 shows that test

anxiety is lower than that of the group without test anxiety in solving problems and seeking help, and the difference is statistically significant $(\mathrm{P}<0.01, \mathrm{P}<0.05)$.

\section{Regression analysis of anxiety state of college students and their mastery of epidemic prevention knowledge and coping style}

With the method of multiple stepwise regression analysis, the contribution rate of independent variables to dependent variables is eliminated step by step, and the variables in the model are tested. Partial regression coefficient shows the effect of independent variables on dependent variables, standard regression coefficient reflects the relative importance among variables, $\mathrm{R}^{2}$ represents the variation of dependent variables explained by independent variables, and the significance test of the model is to compare the variation explained by independent variables with error variation.

Taking epidemic prevention knowledge and coping style as predictors and anxiety as dependent variables, this study explored the relationship between anxiety and epidemic prevention knowledge and coping style of college students (see Table 3).
The results showed that the mastery of epidemic prevention knowledge and positive coping style had a significant reverse predictive effect on anxiety state, while the negative coping style had a significant positive predictive effect on anxiety state, that is, the better the mastery of epidemic prevention knowledge or the more positive coping style, the lower the anxiety level. The more negative the coping style, the higher the anxiety.

\section{DISCUSSION}

In order to alleviate the anxiety of college students, it is necessary to build a stable social support system for them. Family members, schools and communities should pay attention to students' psychological dynamics in time and give them timely help. On the one hand, as far as external forces are concerned, relevant state agencies and news media should actively disseminate objective, positive and professional information to enhance students' confidence in epidemic prevention; On the other hand, for students themselves, we must first accept the present state of anxiety, and proper anxiety is a selfprotection mechanism, which is conducive to keeping us alert to the epidemic situation (Zhang et al. 2019); Secondly, it is necessary to have reasonable emotional catharsis and guidance. When you are isolated at home, you can talk to your family and friends and strengthen your exercise and study.

The results of correlation analysis show that the degree of anxiety of college students is positively correlated with relatively negative coping styles such as patience, escape, venting emotions and fantasy/denial, but not significantly correlated with coping styles such as problem solving and positive and rational explanation. This is basically consistent with previous studies. When faced with stress events, the more negative the coping style, the higher the anxiety level, and the lower the anxiety level (Zhang et al. 2019). The possible explanation is that the change of subjective meaning of human-environment is realized through cognitive evaluation 
activities, which include negative strategies, fantasy, evasion and emphasizing the positive aspects of the situation (Hajduk et al. 2019), and beneficial emotions are generated through cognitive re-evaluation.

This study shows that there are significant differences in coping styles between students with test anxiety and students without test anxiety, and their scores in solving problems and seeking help are lower than those of students without test anxiety. However, the differences in coping styles among students of different genders and arts and sciences classes need further study. In this study, there is no obvious correlation between anxiety and seeking social support, which is inconsistent with the previous research results (Li et al. 2019). The reason may be that during the COVID-19 epidemic, the country adopted active and effective home isolation measures, and college students were accompanied by their families, so that social support was easier to obtain, and there was no need to seek additional social support.

Coping with college students' anxiety is an important topic generally studied by psychologists and educators. The solution of this problem requires the joint efforts of the whole society. Schools should also play an important role in guiding education. Of course, it is more important for college students to overcome their anxiety (Bettmann et al. 2019).

First, strengthen national responsibility. At present, facing the national disaster, every college student needs to strengthen and embody the concept of home and country, civic awareness and youth responsibility.

Second, take social responsibility. For example, some students are brave volunteers in the community, participate in community epidemic prevention and control services, and publicize the moral and legal system; Some students actively contacted foreign classmates and friends to initiate donations of medical materials and so on.

Third, take on family responsibilities. During the anti-epidemic period, they can guide and help their families to face up to and scientifically prevent and control the epidemic, effectively regulate their emotions and rationally arrange their lives. For example, during the epidemic, some students use mindfulness meditation and other methods learned in school psychological classes to help their families adjust their emotions.

During the epidemic period, college teachers actively take measures to guide students to look at the epidemic with a positive and optimistic attitude, learn to adjust themselves in front of the epidemic, and pay attention to leading students to judge the information they receive through self-independence consciousness and learn to correctly judge the value of the information in the face of the impact of internet public opinion information bombardment on the environment.

In order to overcome anxiety, society and schools can provide some help to college students, but more importantly, students themselves should overcome anxiety. There are many ways to reduce stress and relax. Learning to overcome anxiety and adjust psychology is also a compulsory course for college students.

Exercise is a good way to overcome anxiety, and it can exercise the body. Studies have shown that people who have been in an anxious state will also be affected in their physical condition, making their bodies in a subhealthy state and even causing diseases. During exercise, their bodies can relax and relieve the negative effects brought by anxiety.

Strengthen social interaction and overcome solitude. If you become withdrawn, do not communicate with others, and carry everything by yourself, you will increase your psychological burden. Therefore, college students should learn to talk to each other and tell others about their difficulties. Of course, when others need it, they should also learn to listen and give others comfort and suggestions to solve problems. We can share the pressure with each other, and realize that anxiety is more or less a problem for young people of this age, and it is the only way to grow up.

Colleges need to speed up the establishment of a perfect hotline mechanism, especially for students who are unfortunately ill and students in epidemic areas, and help students with professional knowledge and enthusiastic attitude. Affected by the epidemic situation, the social employment of some fresh graduates will change. The psychological consultation hotline mechanism should provide one-to-one services for this purpose, answer students' employment troubles in time, help students resolve their contradictory psychology, and create suitable places for students to vent their psychological pressure.

\section{CONCLUSIONS}

To sum up, during COVID-19 epidemic, there were differences in coping styles among college students of different genders and grades, and some coping styles were related to anxiety. The limitations of this study are as follows: firstly, using convenient sampling instead of random sampling may cause sampling errors; Secondly, this study is only a cross-sectional survey without further investigation and follow-up. All of the above, to a certain extent, lead to the possible limitations of the results of this study. In the future research, the research design will be improved, the sample size will be enlarged, the uniformity of samples in different regions of college students will be ensured, and follow-up will be carried out to further explore related issues.

\section{Acknowledgements: None.}

\section{Conflict of interest: None to declare.}




\section{References}

1. Abuhmaidan Y, Al-Majali S: The Impact of the Coronavirus Pandemic on Mental Health among Al Ain University Students in Light of some Demographic Variables. Psychiatr Danub 2020; 32:482-490

2. Bettmann JE, Prince KC, Hardy CJ, et al: Measuring Anxiety and Depression in Ghanaian and U.S. College Students. Journal of Multicultural Counseling and Development 2019; 47:119-130

3. Fu W, Wang C, Zou L, et al: Psychological Health, Sleep Quality, and Coping Styles to Stress Facing the COVID-19 in Wuhan, China. Translational Psychiatry 2020; 10:225

4. Hajduk M, Heretik A, Vaseckova B, et al: Prevalence and Correlations of Depression and Anxiety Among Slovak College Students. Bratislava Medical Journal 2019; 120:695-698

5. Huang Y: Research and Practice on the Innovative Training Mode of College Students Autonomous Learning Ability under the Background of Internet. The Guide of Science \& Education 2019; 000:189-190

6. Karaşar B, Canli D: Psychological Resilience and Depression during the Covid-19 Pandemic in Turkey. Psychiatr Danub 2020; 32:273-279

7. Li F: Current Situation and Measures of University Students' Financial Aid System. Open Access Library Journal 2019; 06:1-5
8. Li Y, Xiao G: Chinese College Students' English Writing Anxiety and Its Related Factors: A Survey Study. International Journal of Social Science and Education Research 2019; 2:1-9

9. Son C, Hegde S, Smith A, et al: Effects of COVID-19 on College Students' Mental Health in the United States: Interview survey study. Journal of medical internet research 2020; 22: e21279

10. Mubeen, A, Birgit, et al: Depression and Anxiety among International Medical Students in Germany: The Predictive Role of Coping Styles. JPMA. The Journal of the Pakistan Medical Association 2019; 69: 230-234

11. Zhang J, Rong Y: An Analysis of the Current Situation of College Students' Cognition about Thought of Thrift and Exploration of Educational Approaches. Journal of Social Sciences of Shanxi University 2019; 031: 69-72

12. Zhang YF: A Study on the Current Situation and Causes of Online Loans to College Students Born after 1995. Journal of Zaozhuang University 2019; 036: 131-135

13. Zhang ZH: An Empirical Study on Foreign Language Classroom Anxiety of College Students. Sino-American English teaching 2019; 016: 376-386

14. Zhu W, Wei Y, Meng X, et al: The mediation effects of coping style on the relationship between social support and anxiety in Chinese medical staff during COVID-19. BMC Health Services Research 2020; 20: 1-7

Correspondence:

Yinghua Zhao

Yancheng Institute of Technology

Yancheng, Jiangsu, 224051, China

E-mail: yinghuazhaoyh12@snapmail.cc 